\title{
Dynamic Fuzzy Neural-Network Model for Estimating Heavy Metal Concentration in Rice Using Spectral Indices and Environmental Parameters
}

\author{
Xiangnan Liu and Meiling Liu \\ School of Information Engineering, China University of Geosciences
}

China

\section{Introduction}

\subsection{Predictors of heavy metal concentrations in rice}

Several spectral indices and environmental parameters were analyzed in order to determine heavy metal concentrations in rice. Excessive heavy metal concentrations in rice affect its chlorophyll content and cell structure(Huang et al., 2007; Liu et al., 2010b), which can be reflected by hyperspectral reflectance(Yoder and Pettigrew-Crosby 1995; Blackburn 1998; Curran et al., 2001). So, it is feasible to estimate the heavy metal concentrations in plants using hyperspectral data. That is to say, spectral indices deriving from hyperspectral reflectance were utilized to examine rice's physiological responses to heavy metal contamination in paddy fields. Whereas environmental parameters including those relating to soil and weather were important factors for determining heavy metal diffusion in rice. They were selected as input variables on the basis of two important reasons. On the one hand, the involvement of environmental parameters facilitates the application of GDFNN model in different environmental conditions and thus increases the ability of model to be used extensively. On the other hand, the involvement of environmental parameters can improve the accuracy of prediction of heavy metal concentrations in rice leaves. Therefore, in this research, predictors of heavy metal concentrations in rice are composed of spectral indices and environmental parameters.

\subsection{Spectral parameters}

A number of studies have demonstrated that the variation in spectra curve of plant induced by heavy metal pollution occurred in both the visible and the near-infrared (NIR) part of the spectrum (Kooistra et al., 2004). In order to improve the accuracy for estimating heavy metal concentrations in rice, spectral indices sensitive to heavy metal concentrations in rice were selected according to previous studies. Five spectral parameters including red edge position (REP), optimized soil adjusted vegetation index (OSAVI), ratio vegetation index (RVI), normalized difference vegetation index (NDVI) and difference vegetation index (DVI) were selected in this study (Table 1). 


\begin{tabular}{|c|c|c|c|}
\hline Spectral indices & $\begin{array}{l}\text { Wavebands } \\
\text { (nm) }\end{array}$ & Formula & Reference \\
\hline$\overline{\text { REP }}$ & $\begin{array}{l}\text { between } 680 \\
\text { and } 760 \mathrm{~nm}\end{array}$ & $\begin{array}{l}D_{\lambda_{i}}=\frac{R\left(\lambda_{i+1}\right)-R\left(\lambda_{i-1}\right)}{\lambda_{i+1}-\lambda_{i-1}} \text {, when } D_{\lambda_{i}} \text { is maximum } \\
\text { value }\end{array}$ & $\begin{array}{l}\text { Chang and } \\
\text { Coll1ins, } \\
1983\end{array}$ \\
\hline OSAVI $[670,800]$ & 670,800 & OSAVI $=(1+0.5)\left(R_{800}-R_{670}\right) /\left(R_{800}+R_{670}+0.5\right)$ & $\begin{array}{l}\text { Huete et } \\
\text { al., } 1988\end{array}$ \\
\hline RVI[700,750] & 700,750 & $\mathrm{RVI}=\mathrm{R}_{750} / \mathrm{R}_{700}$ & $\begin{array}{l}\text { Schuerger } \\
\text { et al., } 2003\end{array}$ \\
\hline NDVI $[695,760]$ & 695,760 & $\mathrm{NDVI}=\frac{\mathrm{R}_{760}-\mathrm{R}_{695}}{\mathrm{R}_{760}+\mathrm{R}_{695}}$ & $\begin{array}{l}\text { Schuerger } \\
\text { et al., } 2003\end{array}$ \\
\hline DVI[682,734] & 682,734 & $\mathrm{DVI}=\mathrm{R}_{734}-\mathrm{R}_{682}$ & $\begin{array}{l}\text { Kooistra et } \\
\text { al., } 2004\end{array}$ \\
\hline
\end{tabular}

Note: $R_{i}$ is the reflectance of band $i$.

Table 1. Five spectral indices used as input variables of GDFNN model

\subsection{Soil parameters}

The physical and chemical properties of soil, such as $\mathrm{pH}$, soil texture, organic matter (OM), colloid type and granularity, etc. have great influence on the transfer of heavy metals from soil to crop (Jackson and Alloway, 1992; De Vries et al., 2005).That is to say, the mobility and bioavailability of heavy metals are influenced by various soil properties. But different researchers drew different conclusions. But most researchers agreed that, of all physical and chemical properties of soil, soil $\mathrm{pH}$ and organic matter in soil have the greatest effect on the bioavailability of heavy metals, especially for soil $\mathrm{pH}$. Since the extent of soil contamination can also be evaluated by comparing the maximum allowable concentrations (MAC) (National Environmental Protection Agency of China, 2006) of the metals in agricultural land. As soil pH partially governs the speciation and bioavailability of heavy metals, MAC values are adjusted according to soil $\mathrm{pH}$ (Fu et al., 2008). Liao et al.(2008) demonstrated that the contents of $\mathrm{Cr}, \mathrm{Cu}$, $\mathrm{Pb}, \mathrm{Hg}, \mathrm{Ni}$ and $\mathrm{Cd}$ etc. represent an obvious negative correlation with $\mathrm{pH}$ and the content of As represents a positive correlation with $\mathrm{pH}$; that the contents of $\mathrm{Cd}, \mathrm{Cr}, \mathrm{Cu}, \mathrm{Pb}$ and $\mathrm{Hg}$, etc. are positively correlated with $\mathrm{OM}$; the contents of $\mathrm{Ni}$ and As are negatively correlated with $\mathrm{OM}$ by conducting a correlation analysis on seven kinds of heavy metal in soil $\mathrm{pH}$ and $\mathrm{OM}$ in the study area. Likely, other researchers investigated that phytotoxicity and availability of heavy metal is strongly influenced by the $\mathrm{pH}$ and OM of soil (Foy et al., 1978; Fernandes and Henriques, 1991; Das et al., 1997).. Jung and Thornton (1997) investigation of relatively high metal concentrations in rice found it to occur under conditions of decreased $\mathrm{pH}$ and increasing $\mathrm{OM}$ in soil. Other studies also showed that heavy metal concentrations in rice have a significant negative correlation with soil $\mathrm{pH}$ and are positively correlated with $\mathrm{OM}$ (Fu et al., 2008; Liao et al., 2008; Hang et al., 2009).

\subsection{Meteorological parameters}

Since meteorological conditions have influence on the metabolism, transpiration and absorption capabilities of plant roots, they affect the diffusion and translocation of heavy 
metals in plants (Reber, 1989; Kádár, 1995). Some researchers have investigated meteorological factors, such as air temperature, relative humidity, sunlight, precipitation, etc., and have seen that they have important influence on the diffusion of metals in plants (Cui et al., 2004; Pan et al., 2007). The most important factors affecting metal bioavailability in paddy soil are temperature, sunlight and precipitation (Jung and Thornton, 1997; Cheng et al., 2005). So, temperature, sunlight and precipitation can belong to the set of possible predictors of heavy metal concentrations in rice. In this analysis, values for temperature ( $\mathrm{T}$; mean month temperature), sunlight ( $\mathrm{S}$; month accumulative sunlight) and precipitation (P; month accumulative precipitation) during rice growing seasons from July to October in 2008 were measured.

\section{Models for estimating of heavy metal concentrations in rice}

\subsection{Model architecture}

In this paper, a generalized dynamic fuzzy neural network (GDFNN) model was constructed to obtain heavy metal concentrations in rice leaves. GDFNN is a hybrid system that combines the fuzzy logic interference and theories of neural networks. 'Dynamic' indicates the network structure of fuzzy neural network is not predetermined. Namely, the system starts with no rules. Then, rules can be recruited or deleted according to the significance of each rule on output parameters of the structure in existing fuzzy neural network so that not only can the parameters but also the structure can be self-adaptive. GDFNN is a four-layer hybrid neural network with the ability to self-organize its own neurons in the learning process (Wu et al., 2001). The structure of the GDFNN is also shown in Fig. 1.

The layered operation of the GDFNN is as follows:

Layer 1: The input layer-Each neuron in this layer represents an input variable, $\mathrm{x}_{\mathrm{i}}, \mathrm{i}=1 ; 2, \ldots, \mathrm{r}$.

Layer 2: The EBF layer-Each neuron in the EBF layer represents an if-part of a fuzzy rule. The outputs of EBF neurons are computed by products of grades of member function (MF). In this layer physical variables are converted into fuzzy variables. Each MF is in the form of a Gaussian function:

$$
\mu_{i j}\left(x_{i}\right)=\exp \left[\frac{-\left(x_{i}-c_{i j}\right)}{\sigma^{2}{ }_{i j}}\right](i=1, \cdots, r ; j=1, \cdots, u)
$$

where $\mu_{i j}$ is the $\mathrm{i}^{\text {th }}$ membership function in the $\mathrm{j}^{\text {th }}$ neuron, $c_{i j}$ is the centre of the $\mathrm{i}^{\text {th }}$ membership function in the $j^{\text {th }}$ neuron, $\sigma_{i j}$ is the width of the $i^{\text {th }}$ membership function in the $\mathrm{j}^{\text {th }}$ neuron, $r$ is the number of input variables, $u$ is the number of neurons and also represents the numbers of fuzzy rules.

Layer 3: The then-part of a fuzzy rule for the fuzzy model-The output of the $j^{\text {th }}$ neuron in this layer is

$$
\phi_{\mathrm{j}}=\exp \left[-\sum_{i=1}^{r} \frac{\left(x_{i}-c_{i j}\right)}{\sigma^{2}{ }_{i j}}\right](j=1, \cdots, u)
$$

Layer 4: The output layer-Each neuron in this layer represents an output variable as the summation of incoming signals. In this GDFNN a unique output variable is considered: heavy metal concentrations in rice. The output of a neuron in this layer is 


$$
y\left(x_{1}, x_{2}, \cdots, x_{r}\right)=\sum_{j=1}^{u} w_{j} \cdot \phi_{j}
$$

Here, $W_{j}$ the weight of $j$ th rule in neural network.

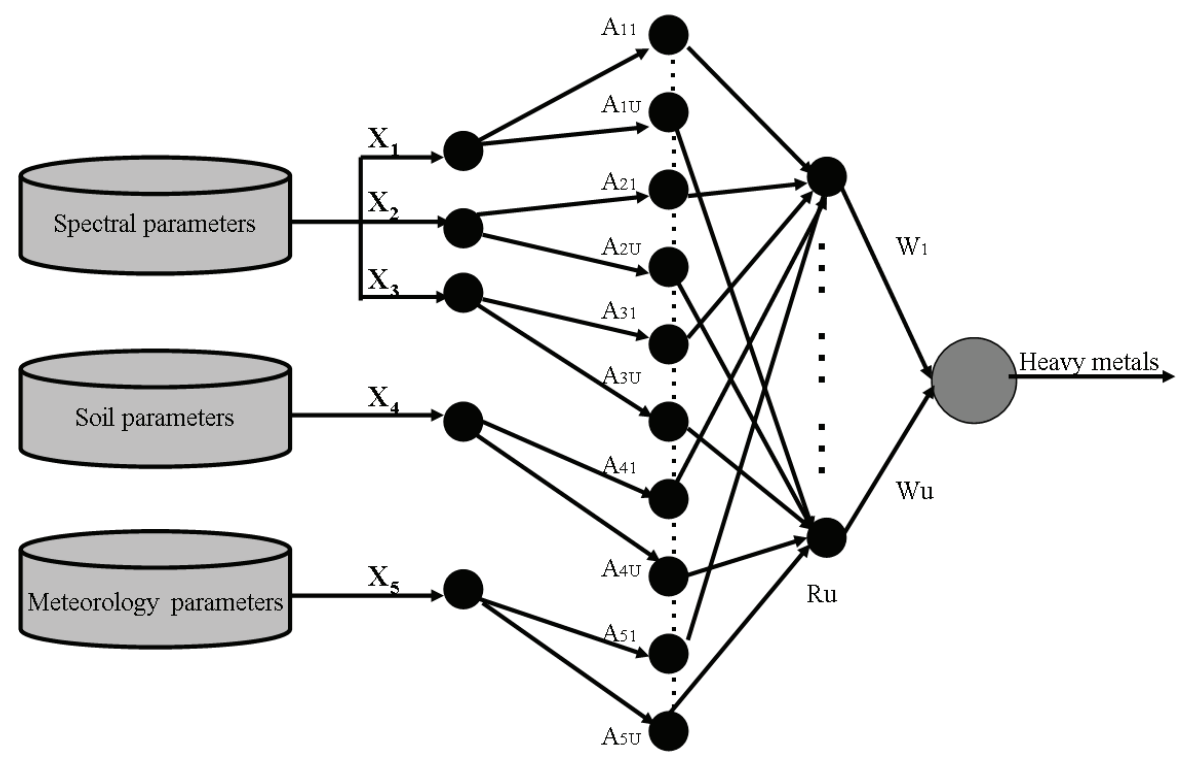

Fig. 1. A simple structure of GDFNN model

\subsection{Model algorithms}

GDFNN is based on ellipsoidal basis function (EBF) and is functionally equivalent to a Takagi-Sugeno-kang fuzzy system (Wu et al., 2001; Leng et al., 2005). Fig. 2 shows the process for learning algorithm in GDFNN.

As seen in Fig. 2, the GDFNN can extract fuzzy rules from the training data without predefined fuzzy rules. In addition, fuzzy rules can be generated automatically according to the systematic error $\left(e_{k}\right)$ and $\varepsilon$-completeness of fuzzy rules. A new rule is created in the case where $m d_{\min }^{k}>k_{d}$ and $e_{k}>k_{e}$. Whereas, if the conditions $m d_{\min }^{k}<k_{d}$ and $e_{k}>k_{e}$ are satisfied, the width of Gaussian function in each rule are adjusted. Else only the consequent parameters are modified under other conditions. However, whether or not an existing rule should be deleted according to the error reduction ratio of each EBF neuron and fuzzy rules to the system performance. If $\eta_{j}<k_{e r r}$, then the rule is deleted. Namely, the less important EBF neurons will be deleted. Based on the learning algorithm in GDFNN, the methods of the structure and parameter learning are based on new adding and pruning techniques and a gradient descent learning algorithm, so GDFNN has high accuracy with a compact structure. 


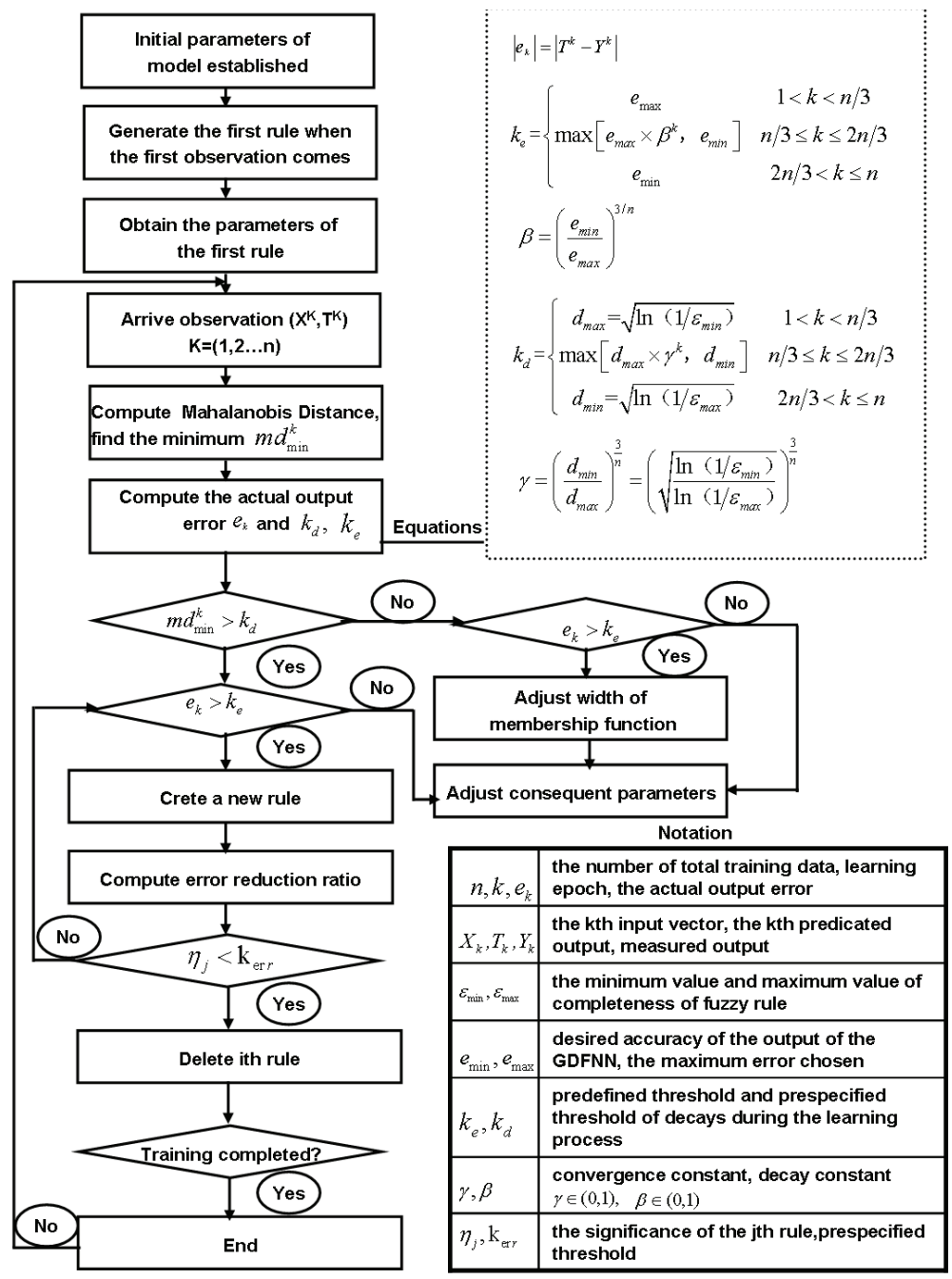

Fig. 2. The process flow chart for the learning algorithm of GDFNN model

\subsection{Model evaluation}

Generally, the root mean square error (RMSE) and absolute percent error (APE) have been used to measure the performance of DFNN (Jang, 1993; Pai et al., 2009). In this study, the parameters were: (i) RMSE ; (ii) APE; and (iii) the correlation coefficient $\left(R^{2}\right)$. The three parameters were computed by:

$$
A P E=\frac{1}{N} \sum_{\mathrm{i}=1}^{\mathrm{N}} \frac{\left|\mathrm{y}_{\mathrm{ai}}-\mathrm{y}_{\mathrm{mi}}\right|}{\left|\mathrm{y}_{\mathrm{ai}}\right|}
$$


where $\mathrm{y}_{a i}, \mathrm{y}_{m i}$, APE are the real-valued output variable, measured output variable, absolute percent error respectively; $\mathrm{N}$ is the sample number. APE provides information on the accuracy that the model can yield using a given data set. The nearer the value approaches 0 , the better the performance of the model.

$$
\text { RMSE }=\sqrt{\frac{\sum_{i=1}^{N}\left(y_{a i}-y_{m i}\right)^{2}}{N-1}}
$$

Here, RMSE is root mean square error between real-valued output variable and measured output variable. The lower RMSE, the better the performance of the model.

$$
R^{2}=\frac{\left[\sum_{i=1}^{N}\left(y_{a i}-\overline{y_{a}}\right) \sum_{i=1}^{N}\left(y_{m i}-\overline{y_{m}}\right)\right]^{2}}{\sum_{i=1}^{N}\left(y_{a i}-\overline{y_{a}}\right)^{2} \sum_{i=1}^{N}\left(y_{m i}-\overline{y_{m}}\right)^{2}}
$$

Here, $\mathrm{R}^{2}, \overline{\mathrm{y}_{\mathrm{m}}}$ and $\overline{\mathrm{y}_{\mathrm{a}}}$ are the correlation coefficient, the average measured output variable and the average real-valued output variable, respectively. $\mathrm{R}^{2}$ represents the correlation between predicted and measured variables. It is assumed that the predicted and measured variables follow a normal distribution. Its value ranges from 0 to 1 . The higher the value of the correlation, the stronger the indication of existing linear relations between the actual and predicted variables.

With the exception of the above three evaluation indicators, a fuzzy rule (labelled $u$ ) was also taken into consideration in this analysis. This is due to the fact that the degree of complexity of the network largely depends on the number of fuzzy rules in the GDFNN model. With sufficiently high accuracy, fewer fuzzy rules are generated in model and the performance of the model improves. Hence, the model has a compact structure as well as a high accuracy.

\section{Methodology}

The crucial procedures for estimating heavy metal concentrations in rice were the selection of input variables and the establishment of a data retrieval model (Fig.3). Firstly, spectral parameters, soil parameters and meteorological parameters were taken into consideration as input variables for the model. The reasons were follows: spectral parameters were selected to examine rice physiological responses to heavy metal contamination, while soil parameters and meteorological parameters were regarded as important factors influencing rice uptake of heavy metal. Moreover, to be useful for practical simulations, specific parameters were needed to satisfy the following requirements: (1) dominant principle: the parameters should be significantly correlated to heavy metal concentrations in crops; (2) ready availability: the parameters could be obtained quickly and at a large scale. Secondly, GDFNN was developed to integrate spectral parameters, soil parameters and meteorological parameters in order to estimate heavy metal concentrations in rice. This model consisted of an input layer, an output layer and several hidden layers, with the hidden layers belonging to fuzzy interference system by carrying out fuzzy reasoning using the structure of neural network. 


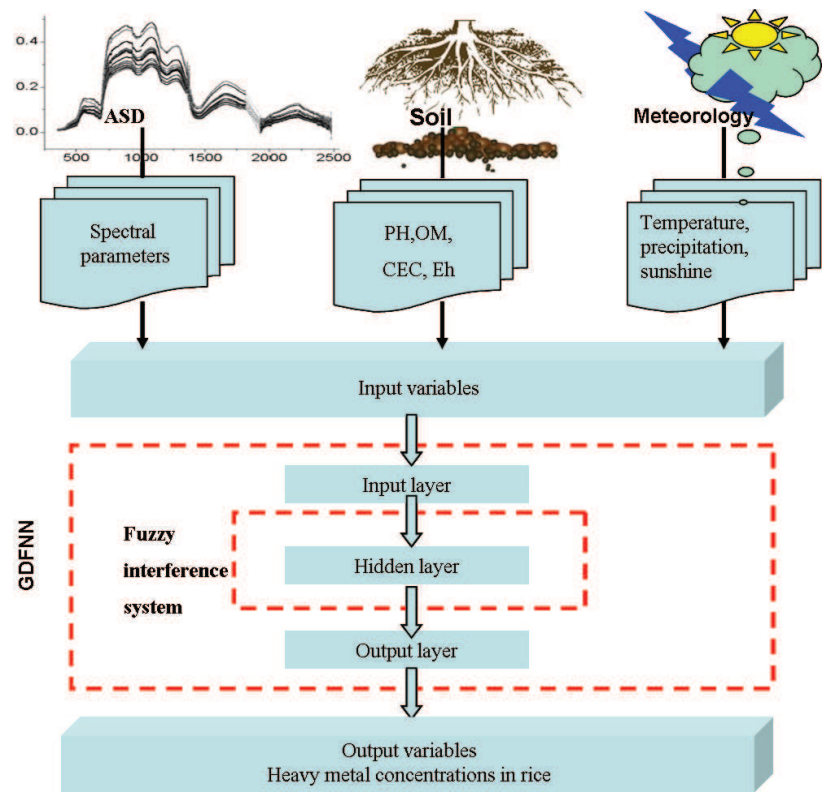

Fig. 3. The general flow chart for estimating heavy metal concentrations in rice

\section{Examples}

\subsection{Site description}

The city of Changchun, Jilin Province in China is an important industrial and agricultural location. Some areas have been contaminated by industrial pollutants, particularly by heavy metals. Suburban farms have soil with copper $(\mathrm{Cu})$ and cadmium $(\mathrm{Cd})$ at higher

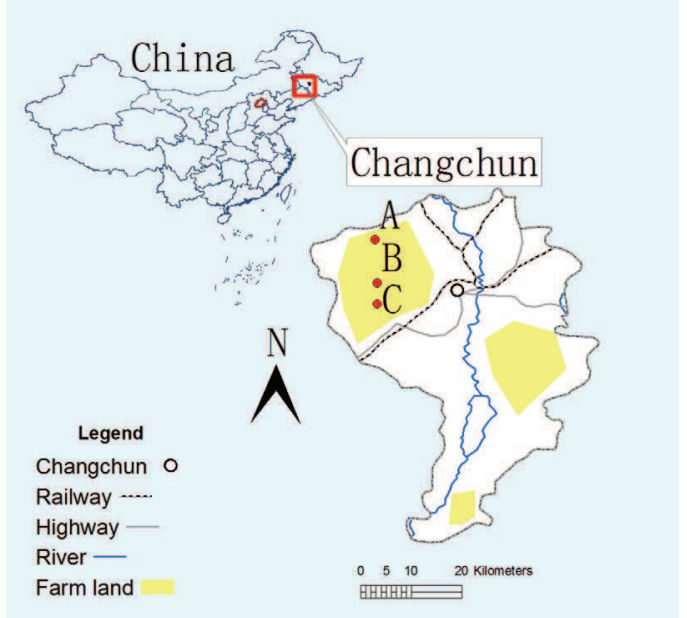

Fig. 4. Location map for experimental sites in Changchun, Jilin Province, China 
concentrations than what is considered to be normal for the area. Three field experiments $\left(43^{\circ}\right.$ $\left.51^{\prime} 34.8^{\prime \prime} \mathrm{N}-43^{\circ} 51^{\prime} 37.0^{\prime \prime} \mathrm{N}, 125^{\circ} 09^{\prime} 07.2^{\prime \prime} \mathrm{E}-125^{\circ} 10^{\prime} 25.3^{\prime \prime} \mathrm{E}\right)$ adjacent to the important industrial district (i.e., the contamination source) in Changchun were selected (Fig. 4). Heavy metal contamination stress levels in the soil of the three field experiments (labeled A, B, and C) varied. The soil and the stress rates were determined according to a soil sample analysis (Table 2) to be at a safe level, level I pollution and level II pollution, respectively. The site is within the temperate continental climate zone with a mean annual rainfall of 522-615 mm, where the land is predominantly black soil, with a $\mathrm{pH}$ of $6.5-7.3$ and $2-4 \%$ of sufficient organic matter. The crop selected in this site was rice which is one of the most important staples in China.

\begin{tabular}{|c|c|c|c|c|c|}
\hline$\overline{\text { Site }}$ & $\begin{array}{l}\text { Geographical } \\
\text { location }\end{array}$ & $\begin{array}{l}\text { Copper } \\
\text { Content } \\
\left(\mathrm{mgkg}^{-1}\right)\end{array}$ & $\begin{array}{l}\text { Cadmium } \\
\text { Content } \\
\left(\mathrm{mgkg}^{-1}\right)\end{array}$ & $\begin{array}{l}\text { Pollution } \\
\text { level }\end{array}$ & $\begin{array}{l}\text { Soil quality } \\
\text { standard* }\left(\mathrm{mgkg}^{-1}\right)\end{array}$ \\
\hline A & $43^{\circ} 52.2^{\prime} \mathrm{N}, 125^{\circ} 10.2^{\prime} \mathrm{E}$ & $68.2 \pm 2.86$ & $0.465 \pm 0.002$ & II & $\begin{array}{c}\Pi \amalg(50 \leq \mathrm{Cu} \leq 400 ; \\
0.3 \leq \mathrm{Cd} \leq 1.0)\end{array}$ \\
\hline B & $43^{\circ} 54.6^{\prime} \mathrm{N}, 125^{\circ} 10.4^{\prime} \mathrm{E}$ & $45.5 \pm 2.44$ & $0.182 \pm 0.002$ & I & $\begin{array}{c}\text { I }(35 \leq \mathrm{Cu}<50 \\
0.2 \leq \mathrm{Cd}<0.3)\end{array}$ \\
\hline $\mathrm{C}$ & $44^{\circ} 06.3^{\prime} \mathrm{N}, 125^{\circ} 10.2 \mathrm{E}$ & $20.4 \pm 2.44$ & $0.093 \pm 0.002$ & Safe & $\begin{array}{l}\text { Safe }(\mathrm{Cu}<20.8 ; \\
\quad \mathrm{Cd}<0.097)\end{array}$ \\
\hline
\end{tabular}

Note: * Soil quality standard according to the Environment Monitoring Centre of China

Table 2 . The location and heavy metal concentrations of the experiment sites

\subsection{Data collecting}

The data collection was carried out in sunny days during a typical rice growth season: 8 July, 4 August, 29 August, 18 September 2008, which corresponded to the seeding, tillering, booting and mature growth stages of rice. All spectral measurements were taken under cloudless or near cloudless conditions between 10:00 and 14:00, using an ASD FieldSpec Pro spectrometer (Analytical Spectral Devices, Boulder, CO. USA). The spectrometer was fitted with $10^{\circ}$ field of view fibre optics, operated in the $350-2500 \mathrm{~nm}$ spectral region with sampling intervals of $2 \mathrm{~nm}$. A BaSO 4 calibration panel was used for determining the black and baseline reflectance. A panel radiance measurement was taken before and after rice measurement using two scans each time. Rice radiance measurements were made at 30-40 sites in each plot and every measurement was recorded as the average of 10 consecutively acquired spectra in order to reduce the noise level. Five spectral indices derived from hyperspectral reflectance were calculated in Table 3.

The measurement of soil property and heavy metal concentrations in rice and soil were taken almost synchronously with rice spectral reflectance measurements. In this context, soil $\mathrm{pH}$ was determined in a paste with a ratio of 1:2.5 soils to water using a $\mathrm{pH}$ meter (Model PHS-3C, Shanghai Precision and Scientific Instrument Co. Ltd.). Soil organic matter was analyzed according to Chinese CRM/RM information center (http://www.gbw114.org). The metal content was analyzed at the Chinese Academy of Agricultural Sciences, Beijing, China. Soil and rice total heavy metals $(\mathrm{Cu}, \mathrm{Zn}, \mathrm{Pb}, \mathrm{Cd}, \mathrm{Cr}, \mathrm{As})$ were determined by flame atomic absorption spectrometry (AAS), after nitric-perchloric acid (2:1) digestion. Soil extractable metals were extracted with $5 \mathrm{mM}$ diethylenetriaminepentaacetic acid (DTPA)/10 $\mathrm{mM} \mathrm{CaCl}_{2} / 100 \mathrm{mM}$ triethanolamine at $\mathrm{pH} 7.3$ (Lindsay and Norvell, 1978). The measured meteorological data for the Changchun station were obtained from the CMA 
(http://cdc.cma.gov.cn/).Soil parameters and meteorological data were also summarized in Table 3.

\begin{tabular}{|c|c|c|c|c|c|c|c|}
\hline Variables & Abbreviation & Unit & Min & Max & Medium & Mean & SD \\
\hline Red edge position & REP & $\mathrm{nm}$ & 694 & 730 & 695 & 699 & 10 \\
\hline $\begin{array}{l}\text { Optimized soil } \\
\text { adjusted } \\
\text { vegetation index }\end{array}$ & OSAVI & - & 0.24 & 0.56 & 0.39 & 0.38 & 0.07 \\
\hline $\begin{array}{l}\text { Normalized } \\
\text { difference } \\
\text { vegetation index }\end{array}$ & NDVI & - & 0.19 & 0.68 & 0.39 & 0.40 & 0.13 \\
\hline $\begin{array}{l}\text { Ratio vegetation } \\
\text { index }\end{array}$ & RVI & - & 1.30 & 3.68 & 1.87 & 2.06 & 0.72 \\
\hline $\begin{array}{l}\text { Difference } \\
\text { vegetation index }\end{array}$ & DVI & - & 0.08 & 0.36 & 0.18 & 0.19 & 0.06 \\
\hline $\mathrm{pH}$ & $\mathrm{pH}$ & - & 6.5 & 7.0 & 6.8 & 6.8 & 0.1 \\
\hline Organic matter & $\mathrm{OM}$ & $\%$ & 2.4 & 3.2 & 2.7 & 2.8 & 0.15 \\
\hline Sunlight & $S$ & hours & 149.3 & 261.3 & - & - & - \\
\hline Temperature & $\mathrm{T}$ & $\circ$ & 9.5 & 23.5 & - & - & - \\
\hline Precipitation & $\mathrm{P}$ & $\mathrm{mm}$ & 17 & 199.8 & - & - & - \\
\hline $\begin{array}{l}\mathrm{Cu} \text { concentration } \\
\text { in rice leaves }\end{array}$ & $\mathrm{Cu}$ & mgkg-1 & 18.77 & 31.12 & 23.34 & 24.29 & 2.87 \\
\hline $\begin{array}{l}\mathrm{Cd} \text { concentration } \\
\text { in rice leaves }\end{array}$ & $\mathrm{Cd}$ & mgkg-1 $^{-1}$ & 0.036 & 0.042 & 0.039 & 0.039 & 0.001 \\
\hline
\end{tabular}

Notes: values for $\mathrm{T}$ (mean month temperature), $\mathrm{S}$ (month accumulative sunlight) and $\mathrm{P}$ (month accumulative precipitation).SD, Standard deviation

Table 3. Basic statistics of the measured spectral indices and environmental parameters in field experimental sites

\subsection{Data processing}

In this study, to avoid data saturation, the input variables in this model were normalized, based on their possible ranges using the following equation:

$$
x_{\text {norm }}=\frac{x_{i}-x_{\min }}{x_{\max }-x_{\min }}
$$

where $\mathrm{x}_{\mathrm{i}}, x_{\min }, x_{\max }$ and $\mathrm{x}_{\text {norm }}$ are the real-valued input variable, the minimum input variable, maximum input variable and its normalized value respectively. The output from the GDFNN model is an indexed value that corresponds to the input variable. To get the real-predicted value, the indexed output value needs to be de-normalized according to the following equation:

$$
\mathrm{y}_{\mathrm{ai}}=\mathrm{y}_{\min }+\mathrm{y}_{\text {norm }}\left(\mathrm{y}_{\max }-\mathrm{y}_{\min }\right)
$$

Where $\mathrm{y}_{a i}, \mathrm{y}_{\min }, \mathrm{y}_{\max }$ and $\mathrm{y}_{\text {norm }}$ are the real-predicted value, the minimum and maximum values of the real-valued output, and the indexed output value from the GDFNN model respectively. 


\section{Results and discussions}

Since the maximal absolute value of the difference of heavy metal concentrations in rice leaves from different contaminated levels occurred at the tillering growth stage, this indicates the best stage for estimating heavy metal concentrations is at that stage (Liu et al., 2010a). Therefore, in this research, 138 training data sets and 69 test data sets from the tillering growth stage of rice were obtained for different levels of heavy metal pollution. Considering that spectral parameters were considered as dominant input variables and environmental parameters as complementary input variables of GDFNN model. In GDFNN, five parameters were taken as input variables, i.e., three spectral parameters, one soil parameter and one meteorological parameter, while the individual concentrations of $\mathrm{Cu}$ and $\mathrm{Cd}$ in rice served as output variables. By trying different combinations of input data sets (three selected from the five spectral parameters, the fourth was taken from the two soil parameters, and the fifth came from the three meteorological parameters). 60 groups $\left(C_{5}^{3} \times C_{3}^{1} \times C_{2}^{1}=60\right)$ different input parameters were developed (Table 4). Fuzzy rules $(\mathrm{u})$, APE, $\mathrm{R}^{2}$ and RMSE of all groups for estimating $\mathrm{Cu}$ concentration and $\mathrm{Cd}$ concentration are shown (Fig. 5). From Fig. 5, regardless of the group for $\mathrm{Cu}$ and $\mathrm{Cd}$, fewer $\mathrm{u}$ were achieved in GDFNN, with $u$ ranging from 2 to 14 . Additionally, the more $u$ in the developed model, the lower value APE. When it comes to $\mathrm{R}^{2}$ and RMSE, $\mathrm{R}^{2}$ of all groups, the values were over 0.6 and the RMSE of all models were below 2.5. According to the parameters for assessing the performance of GDFNN, the optimal group should have a low RMSE and APE, and an R2 value close to 1 . Four groups of optimal combined parameters for estimating $\mathrm{Cd}$ concentration are displayed in Fig. 6. Their input variables were NDVI-RVI-DVI-OM-P, NDVI-RVI-DVI-OM-S, NDVI-RVI-DVI-pH-P and NDVI-RVI-DVI-pH-S. All four groups were highly accurate and had compact architectures. Specifically, u was nearly 10, while $\mathrm{R}^{2}$ was over 0.9 , and APE was below $1.0 \%$. With respect to combined parameters, the three best spectral parameters (NDVI, RVI and DVI) and soil parameters ( $\mathrm{pH}$ and OM) were found as the main factors controlling the availability and concentration of $\mathrm{Cd}$ in rice. Meanwhile, precipitation $(\mathrm{P})$ and sunlight $(\mathrm{S})$ were shown to be chief factors affecting $\mathrm{Cd}$ concentration in rice. However, temperature $(\mathrm{T})$ was determined to be a negligible factor influencing $\mathrm{Cd}$ concentration in rice. Similarly, four groups of optimal combined parameters for estimating $\mathrm{Cu}$ concentration are displayed in Fig.7. Their input variables were OSAVI-NDVI-DVI-OMP, REP-NDVI-DVI-OM-T, OSAVI-RVI-DVI-pH-P and REP-OSAVI-NDVI-pH-T. All four groups were highly accurate and had compact architectures. Specifically, $\mathrm{u}$ was nearly $10, \mathrm{R}^{2}$ was over 0.9 , APE was below 1.5\%.Concerning combined parameters, it was observed that spectral parameters differed with respect to soil parameters and meteorological parameters. The main factors controlling the availability of $\mathrm{Cu}$ were $\mathrm{pH}$ and $\mathrm{OM}$ in soil, and this affected the $\mathrm{Cu}$ concentration in rice. Precipitation $(\mathrm{P})$ and temperature $(\mathrm{T})$ mainly affectd $\mathrm{Cu}$ concentration in rice. However, sunlight $(S)$ was merely a negligible factor in influencing $\mathrm{Cu}$ concentration in rice.

To examine whether combined parameters can improve the performance of predictions for heavy metal concentrations in rice, a comparison between the application of GDFNN with combined parameters (including spectral parameters, soil parameters and meteorological parameters) and simply with spectral parameters alone was made (Fig.8). The linear fitting equation between predicted heavy metal concentrations and measured heavy metal concentrations gave the following results through the application of these two methods with the different respective input variables:

1. Five spectral parameters including REP, OSAVI, NDVI, DVI and RVI for estimating Cu and $\mathrm{Cd}$ concentration in rice are: 


$$
\begin{aligned}
\mathrm{y}_{\mathrm{ai} c u} & =0.8353 \mathrm{y}_{\mathrm{mi} c u}+3.9194 \\
\mathrm{y}_{\text {ai } c d} & =0.8150 \mathrm{y}_{\text {mi } c d}+7.2685
\end{aligned}
$$

Here, $\mathrm{R}^{2}=0.7848$ and 0.8235 respectively. Values for $\mathrm{y}_{\text {aicu }}$ and $\mathrm{y}_{\text {aicd }}$ predicted $\mathrm{Cu}$ and $\mathrm{Cd}$ concentration respectively, while $\mathrm{y}_{\text {micu }} \mathrm{y}_{\text {micd }}$ are measured for $\mathrm{Cu}$ and $\mathrm{Cd}$ concentration respectively.

2. The best model of combined parameters for estimating $\mathrm{Cu}$ and $\mathrm{Cd}$ concentration in rice are:

$$
\begin{aligned}
\mathrm{y}_{\text {aicu }} & =0.9921 \mathrm{y}_{\text {mi } c u}+0.1924 \\
\mathrm{y}_{\text {ai } c d} & =0.9967 \mathrm{y}_{\text {mi } c d}+0.1278
\end{aligned}
$$

Here, $\mathrm{R}^{2}=0.9929$ and 0.9921 respectively. Values for $\mathrm{y}_{\text {aicu }}$ and $\mathrm{y}_{\text {aicd }}$ predicted $\mathrm{Cu}$ and $\mathrm{Cd}$ concentration respectively, while $\mathrm{y}_{\text {micu }} \mathrm{y}_{\text {micd }}$ are measured $\mathrm{Cu}$ and $\mathrm{Cd}$ concentration respectively.

\begin{tabular}{rlrl}
\hline \multicolumn{1}{c}{ Group } & \multicolumn{1}{c}{ Parameters } & Group & \multicolumn{1}{c}{ Parameters } \\
\hline 1 & REP, OSAVI, NDVI, OM, P & 31 & REP, OSAVI, NDVI, pH, P \\
2 & REP, OSAVI, RVI, OM, P & 32 & REP, OSAVI, RVI, pH, P \\
3 & REP, OSAVI, DVI, OM, P & 33 & REP, OSAVI, DVI, pH, P \\
4 & REP, NDVI, RVI, OM, P & 34 & REP, NDVI, RVI, pH, P \\
5 & REP, NDVI, DVI, OM, P & 35 & REP, NDVI, DVI, pH, P \\
6 & REP, RVI, DVI, OM, P & 36 & REP, RVI, DVI, pH, P \\
7 & OSAVI, NDVI, RVI, OM, P & 37 & OSAVI, NDVI, RVI, pH, P \\
8 & OSAVI, NDVI, DVI, OM, P & 38 & OSAVI, NDVI, DVI, pH, P \\
9 & OSAVI, RVI, DVI, OM, P & 39 & OSAVI, RVI, DVI, pH, P \\
10 & NDVI, RVI, DVI, OM, P & 40 & NDVI, RVI, DVI, pH, P \\
11 & REP, OSAVI, NDVI, OM, S & 41 & REP, OSAVI, NDVI, pH, S \\
12 & REP, OSAVI, RVI, OM, S & 42 & REP, OSAVI, RVI, pH, S \\
13 & REP, OSAVI, DVI, OM, S & 43 & REP, OSAVI, DVI, pH, S \\
14 & REP, NDVI, RVI, OM, S & 44 & REP, NDVI, RVI, pH, S \\
15 & REP, NDVI, DVI, OM, S & 45 & REP, NDVI, DVI, pH, S \\
16 & REP, RVI, DVI, OM, S & 46 & REP, RVI, DVI, pH, S \\
17 & OSAVI, NDVI, RVI, OM, S & 47 & OSAVI, NDVI, RVI, pH, S \\
18 & OSAVI, NDVI, DVI, OM, S & 48 & OSAVI, NDVI, DVI, pH, S \\
19 & OSAVI, RVI, DVI, OM, S & 49 & OSAVI, RVI, DVI, pH, S \\
20 & NDVI, RVI, DVI, OM, S & 50 & NDVI, RVI, DVI, pH, S \\
21 & REP, OSAVI, NDVI, OM, T & 51 & REP, OSAVI, NDVI, pH, T \\
22 & REP, OSAVI, RVI, OM, T & 52 & REP, OSAVI, RVI, pH, T \\
23 & REP, OSAVI, DVI, OM, T & 53 & REP, OSAVI, DVI, pH, T \\
24 & REP, NDVI, RVI, OM, T & 54 & REP, NDVI, RVI, pH, T \\
25 & REP, NDVI, DVI, OM, T & 55 & REP, NDVI, DVI, pH, T \\
26 & REP, RVI, DVI, OM, T & 56 & REP, RVI, DVI, pH, T \\
27 & OSAVI, NDVI, RVI, OM, T & 57 & OSAVI, NDVI, RVI, pH, T \\
28 & OSAVI, NDVI, DVI, OM, T & 58 & OSAVI, NDVI, DVI, pH, T \\
29 & OSAVI, RVI, DVI, OM, T & 59 & OSAVI, RVI, DVI, pH, T \\
30 & NDVI, RVI, DVI, OM, T & 60 & NDVI, RVI, DVI, pH, T \\
\hline
\end{tabular}

Note: REP-red edge position, OSAVI-optimized soil-adjusted vegetation index, ratio RVI-vegetation index, NDVI-normalized difference vegetation index, DVI-difference vegetation index), $\mathrm{pH}, \mathrm{OM}$ organism matter for soil, T-temperature, S-sunlight, P- precipitation

Table 4. Sixty groups of combined parameters as input variables for GDFNN 
Based on the above analysis, the GDFNN model using combined parameters as input variables showed better prediction performance than that with only five spectral parameters. It confirmed that soil parameters and meteorological parameters had improved the accuracy in estimating $\mathrm{Cu}$ and $\mathrm{Cd}$ concentration in rice. Yet it should be noted that three different experiment sites are adjacent, consequently the difference in the physical and chemical properties of soil, and meteorological condition are subtle. A GDFNN model using combined parameters requires testing under different environmental conditions. In the current study, we focused on proposing a new methodology and developing ideas for estimating heavy metal concentrations in crop by using spectral parameters and environmental parameters as input variables of GDFNN.
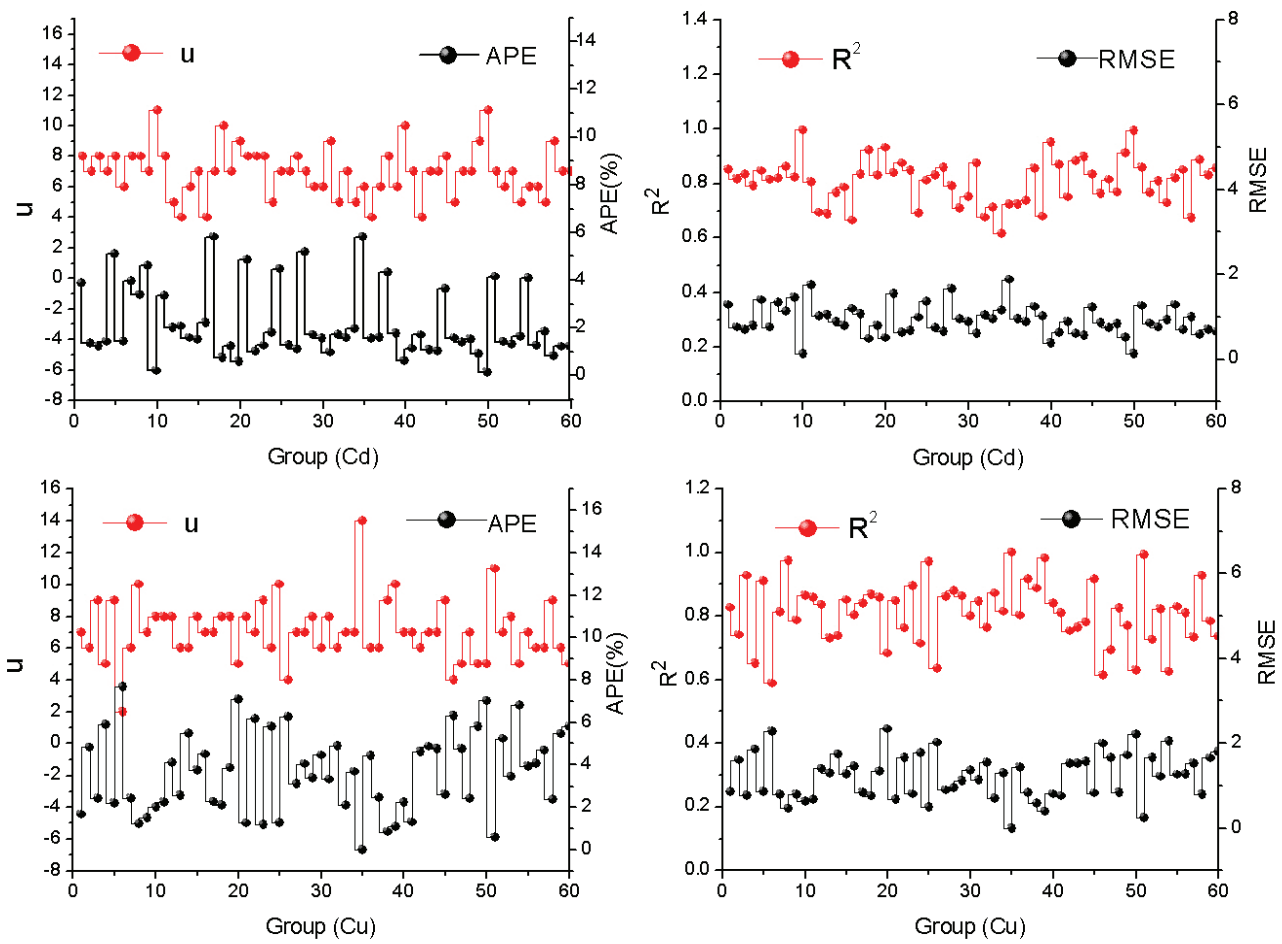

Fig. 5. The four evaluation parameters ( $u, A P E, R^{2}$ and RMSE) results for sixty groups of combined parameters as input variables for estimating $\mathrm{Cu}$ and $\mathrm{Cd}$ concentration in rice leaves. Each group consists of parameters according to Table 4. 

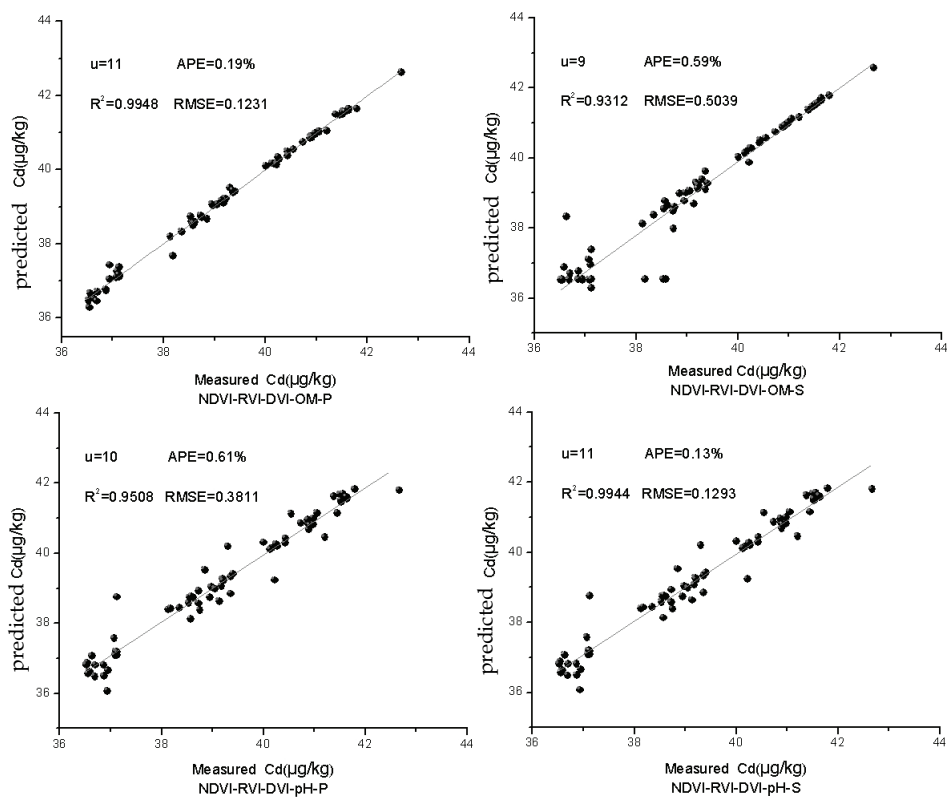

Fig. 6. Measured and predicted $\mathrm{Cd}$ concentration in rice leaves for four groups of optimal combined parameters using GDFNN
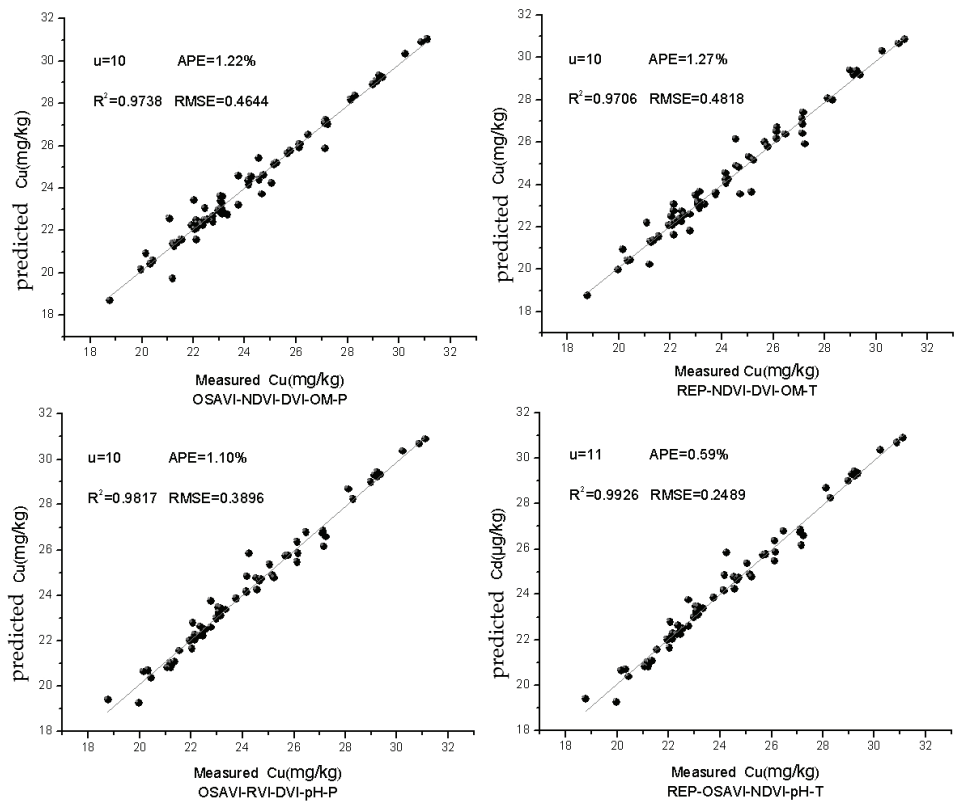

Fig. 7. Measured and predicted $\mathrm{Cu}$ concentration in rice leaves for four groups of optimal combined parameters using GDFNN 

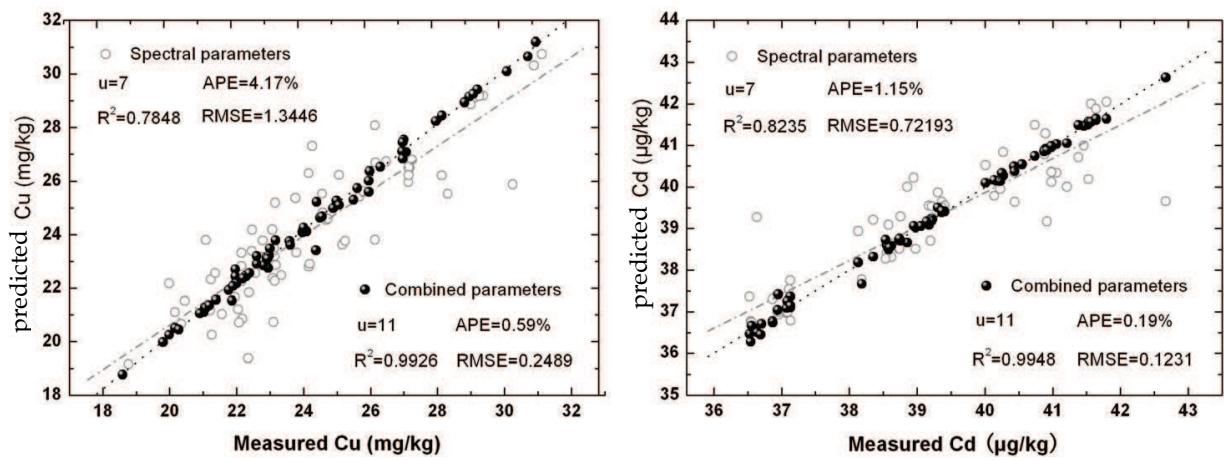

Fig. 8. Comparison of predicted $\mathrm{Cu}$ and $\mathrm{Cd}$ concentration in rice leaves using spectral parameters and combined parameters as input variables for GDFNN

\section{Conclusions}

The aim of this study is to develop a GDFNN model based on fuzzy theory and neural network theory to predict heavy metal concentrations in rice. Spectral indices and environmental parameters were integrated as input variables. Spectral indices were utilized to examine rice's physiological responses to heavy metal contaminations $(\mathrm{Cu}$ and $\mathrm{Cd})$ in paddy fields, while environmental parameters including those relating to soil and weather were important factors for determining heavy metal diffusion in rice. Five parameters, three of which were selected from the five spectral parameters (REP, OSAVI, NDVI, DVI, RVI), one of which came from the two soil parameters $(\mathrm{pH}, \mathrm{OM})$, with the final one coming from the three meteorological parameters ( $T, S, P$ ) were used as input variables in GDFNN. Additionally, different combined parameters were treated as input variables in order to achieve the best GDFNN prediction for heavy metal concentrations in rice. The analysis revealed that the best input variables in predicting $\mathrm{Cu}$ concentrations in rice were the REP, OSAVI, NDVI, $\mathrm{pH}$ and T, where this model had $\mathrm{u}, \mathrm{APE}, \mathrm{R}^{2}$ and RMSE values of $11,0.59 \%$, 0.9926 and 0.2489 respectively. While the best input variables in predicting $\mathrm{Cu}$ concentrations in rice were the NDVI, RVI, DVI, OM and P, which had respective $u, A P E$, and $\mathrm{R}^{2}$ values of $11,0.19 \%, 0.9948$ and 0.1231 . It indicated that the GDFNN developed in this study had a high accuracy as well as a compact structure (i.e. fewer fuzzy rules: $u=11, R^{2}$ was over 0.99 nearly 1). Compared with only spectral parameters as input variables of GDFNN, the use of combined parameters as input variables showed slightly better performance in estimating $\mathrm{Cu}$ and $\mathrm{Cd}$ concentrations in rice. After testing a trial set, our results showed that the GDFNN developed using fewer input variables can accurately estimate heavy metal concentrations in rice, thus aiding the assessment of pollution levels of heavy metals in soil. It can be concluded that by using a GDFNN model, hyperspectral parameters and environmental parameters can provide sufficient information to detect the level of pollutants in field operations efficiently.

\section{Reference}

Blackburn, G.A. (1998). Quantifying chlorophylls and caroteniods at leaf and canopy scales: An evaluation of some hyperspectral approaches. Remote Sensing of Environment, $66,273-285$. 
Chang, S. H., \&Coll1ins, W.( 1983). Confirmation of the airborne biogeophysica mineral exploration technique using laboratory methods. Economic Geology, 78, 723-736.

Cheng, W.D., Zhang, G.P., Yao, H.G., \&Tang, M.L.(2005). Effect of grain position within a panicle and variety on $\mathrm{As}, \mathrm{Cd}, \mathrm{Cr}, \mathrm{Ni}, \mathrm{Pb}$ concentrations in japonica rice. Rice Science, 12: 48-56(in Chinese).

Cui, Y.J., Zhu, Y.G., Zhai, R.H., Chen, D.Y., Huang, Y.Z., Qiu, Y., \& Liang, J.Z. (2004). Transfer of metals from soil to vegetables in an area near a smelter in Nanning, China. Environment International, 30, 785-791.

Curran, P.J., Dungan, J.L., \& Peterson, D.L. (2001). Estimating the foliar biochemical concentration of leaves with reflectance spectrometry testing the Kokaly and Clark methodologies. Remote Sensing of Environment, 76, 349-359.

Das, P., Samantaray, S., \& Rout, G.R. (1997). Studies on cadmium toxicity in plants: A review. Environmental Pollution, 98, 29-36.

De Vries, W., Curlik, J., Muranyi, A., Alloway, B., \& Groenenberg, B.J. (2005). Assessment of relationships between total and reactive concentrations of cadmium, copper, lead and zinc in Hungarian and Slovakian soils. Ekologia-Bratislava, 24, 152-169.

Fernandes, J. C. \&Henriques, F. S. (1991). Biochemical, physiological, and structural effects of excess copper in plants. The Botanical Reivew, 57, 246-266.

Foy, C. D., Chancy, R. L. \& White, M. C. (1978) The physiology of metal toxicity in plants. Annual Review of Plant Physiology, 29, 511-566.

Fu, J.J., Zhou, Q.F., Liu, J.M., Liu, W., Wang, T., Zhang, Q.H., \& Jiang, G.B. (2008). High levels of heavy metals in rice (Oryza sativa L.) from a typical E-waste recycling area in southeast China and its potential risk to human health. Chemosphere, 71, 12691275.

Hang, X.S., Wang, H.Y., Zhou, J.M., Ma, C.L., Du, C.W., \& Chen, X.Q. (2009). Risk assessment of potentially toxic element pollution in soils and rice (Oryza sativa) in a typical area of the Yangtze River Delta. Environmental Pollution, 157, 2542-2549.

Huang, S.S., Liao, Q.L., Hua, M., Wu, X.M., Bi, K.S., Yan, C.Y., Chen, B., \& Zhang, X.Y. (2007). Survey of heavy metal pollution and assessment of agricultural soil in Yangzhong district, Jiangsu Province, China. Chemosphere, 67, 2148-2155.

Huete, A. R. (1988). A soil vegetation adjusted index (SAVI). Remote Sensing of Environment, 25,295-309.

Jackson, A.P., \&Alloway, B.J.(1992). The transfer of cadmium from agricultural soils to the human food chain. In: D.C. Adriano Ed.., Biogeochemistry of Trace Metals. Lewis, Boca Raton, FL, pp. 109-158.

Jang J.S.R.(1993). ANFIS: adaptive-network-based fuzzy inference system. IEEE Transactions on Systems Man and Cybernetics, 23, 665-684.

Jung, M.C., \& Thornton, I. (1997). Environmental contamination and seasonal variation of metals in soils, plants and waters in the paddy fields around a $\mathrm{Pb}-\mathrm{Zn}$ mine in Korea. Science of the Total Environment, 198, 105-121.

Kádár, I.(1995). Effect of heavy metal load on soil and crop.Acta Agronomica Hungarica, 43, 3-9.

Kooistra, L., Salas, E.A.L., Clevers, J., Wehrens, R., Leuven, R., Nienhuis, P.H., \&Buydens, L.M.C.(2004). Exploring field vegetation reflectance as an indicator of soil contamination in river floodplains. Environmental Pollution, 127, 281-290. 
Leng, G., McGinnity, T.M., \&Prasad, G.(2005). An approach for on-line extraction of fuzzy rules using a self-organising fuzzy neural network. Fuzzy Sets and Systems, 150, 211-243.

Liao, F.Q., Zhou, S.L., Zhang, H.F., Wu, S.H., \& Zhao, Q.G. (2008). Spatial distribution and changes of heavy metals of agricultural lands in typical pregrading coast in Dongtai City, Jiangsu Province, China. Chinese Geographical Science, 18, 276-283.

Lindsay,W. L.,\&Norvell, W. A.(1978). Development of a DTPA soil test for zinc, iron, manganese, and copper. Soil Science Society of America Journal, 42, 421-428.

Liu,M. L., Liu ,X. N.,Li,M., Fang, M. H., \&Chi,W. X.(2010a). Neural-network model for estimating leaf chlorophyll concentration in rice under stress from heavy metals using four spectral indices. Biosystems Engineering, 6, 223-233.

Liu,Y.,Chen,H.,Wu,G.F., \&Wu,X.G.(2010b). Feasibility of estimating heavy metal concentrations in Phragmites australis using laboratory-based hyperspectral dataA case study along Le'an River, China. International Journal of Applied Earth Observation and Geoinformation (in press). http:/ / doi:10.1016/j.jag.2010.01.003

National Environmental Protection Agency of China, 2006. Farmland environmental quality evaluation standards for edible agriculture products.. State Environmental Protection Administration, China. HJ332-2006.

Pai, T.Y., Wan, T.J., Hsu, S.T., Chang, T.C., Tsai, Y.P., Lin, C.Y., Su, H.C., \& Yu, L.F. (2009). Using fuzzy inference system to improve neural network for predicting hospital wastewater treatment plant effluent. Computers \& Chemical Engineering, 33, $1272-$ 1278.

Pan,W.J.,Jiang,C.Y.,Tang,Y.J.,Li, J.X. \&Huang,J.G(2007). Effect of environment on Cadmium and lead content in tobacco. Soil, 39 (3): 369-374(in Chinese).

Reber, H. H.(1989). Threshold levels of cadmium for soil respiration and growth of spring wheat (Triticum aestivumL.), and difficulties with their determination. Biology and Fertility of Soils, 7,152-157.

Schuerger, A.C., Capelle, G.A., Di Benedetto, J.A., Mao, C.Y., Thai, C.N., Evans, M.D., Richards, J.T., Blank, T.A., \& Stryjewski, E.C. (2003). Comparison of two hyperspectral imaging and two laser-induced fluorescence instruments for the detection of zinc stress and chlorophyll concentration in bahia grass (Paspalum notatum Flugge.). Remote Sensing of Environment, 84, 572-588.

Wu, S.Q., Er, M.J., \& Gao, Y. (2001). A fast approach for automatic generation of fuzzy rules by generalized dynamic fuzzy neural networks. IEEE Transactions on Fuzzy Systems, 9, 578-594.

Yoder, B.J., \& Pettigrewcrosby, R.E. (1995). Predicting Nitrogen and Chlorophyll Content and Concentrations from Reflectance Spectra $(400-2500 \mathrm{~nm})$ at Leaf and Canopy Scales. Remote Sensing of Environment, 53, 199-211. 


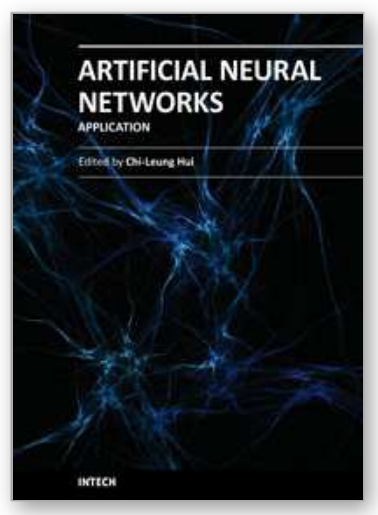

\author{
Artificial Neural Networks - Application \\ Edited by Dr. Chi Leung Patrick Hui
}

ISBN 978-953-307-188-6

Hard cover, 586 pages

Publisher InTech

Published online 11, April, 2011

Published in print edition April, 2011

This book covers 27 articles in the applications of artificial neural networks (ANN) in various disciplines which includes business, chemical technology, computing, engineering, environmental science, science and nanotechnology. They modeled the ANN with verification in different areas. They demonstrated that the ANN is very useful model and the ANN could be applied in problem solving and machine learning. This book is suitable for all professionals and scientists in understanding how ANN is applied in various areas.

\title{
How to reference
}

In order to correctly reference this scholarly work, feel free to copy and paste the following:

Xiangnan Liu and Meiling Liu (2011). Dynamic Fuzzy Neural-Network Model for Estimating Heavy Metal Concentration in Rice Using Spectral Indices and Environmental Parameters, Artificial Neural Networks Application, Dr. Chi Leung Patrick Hui (Ed.), ISBN: 978-953-307-188-6, InTech, Available from: http://www.intechopen.com/books/artificial-neural-networks-application/dynamic-fuzzy-neural-network-modelfor-estimating-heavy-metal-concentration-in-rice-using-spectral-i

\section{INTECH}

open science | open minds

\section{InTech Europe}

University Campus STeP Ri

Slavka Krautzeka 83/A

51000 Rijeka, Croatia

Phone: +385 (51) 770447

Fax: +385 (51) 686166

www.intechopen.com

\section{InTech China}

Unit 405, Office Block, Hotel Equatorial Shanghai

No.65, Yan An Road (West), Shanghai, 200040, China

中国上海市延安西路65号上海国际贵都大饭店办公楼 405 单元

Phone: +86-21-62489820

Fax: +86-21-62489821 
(C) 2011 The Author(s). Licensee IntechOpen. This chapter is distributed under the terms of the Creative Commons Attribution-NonCommercialShareAlike-3.0 License, which permits use, distribution and reproduction for non-commercial purposes, provided the original is properly cited and derivative works building on this content are distributed under the same license. 